\title{
Tidal activity rhythms and depth distribution of rocky shore fish in an altered intertidal environment
}

\author{
C. Faria $\cdot$ V. C. Almada
}

Received: 18 June 2007 /Revised: 7 April 2008 / Accepted: 23 April 2008 / Published online: 27 May 2008

(C) Springer-Verlag and ISPA 2008

\begin{abstract}
In this note we report on changes of activity level of littoral fish and their use of different microhabitats in an altered intertidal environment, where intertidal fish are never emersed and turbulence is confined to high tides. Despite these atypical conditions, the structure of the assemblage is basically the same found in a typical rockyshore situation. Two intertidal fish known to possess internal tidal rhythms, Lipophrys pholis and Coryphoblennius galerita, retain those rhythms in these altered conditions, and the associated social changes in L. pholis are also retained. These observations support the studies of Gibson (1971), who showed that changes in hydrostatic pressure were of prime importance in keeping the tidal rhythm entrained. The subtidal Parablennius pilicornis, on the contrary, is more active during low tide than at high tide. The hypothesis that some subtidal species are excluded from the intertidal by a turbulence-avoiding mechanism is discussed.
\end{abstract}

Keywords Tidal rhythms · Rocky-shore fish .

Depth distribution $\cdot$ Blenniidae

\section{Introduction}

Most studies on the vertical distribution of littoral fishes were based on observations made during low tide, a period

Communicated by E. Goncalves

C. Faria $(\bowtie) \cdot$ V. C. Almada

Unidade de Investigação em Eco-Etologia,

Instituto Superior de Psicologia Aplicada,

R. Jardim do Tabaco 34,

P-1149-041 Lisboa, Portugal

e-mail: cfaria@ispa.pt when intertidal fishes are confined to shelters like pools, crevices or spaces beneath boulders (Gibson 1972, 1982, 1986; Horn et al. 1999; Faria and Almada 2001). However, the information collected at low tide probably provides a biased picture of the behaviour and ecology of these fish assemblages, since they provide only information on the period when fish are least active (Gibson 1967).

Experimental laboratory studies on activity rhythms consistently show that the level of activity of intertidal fish tends to oscillate with the tidal cycle, being lowest at low tide (e.g. Gibson 1967, 1970, 1971). These tidal rhythms seem to be endogenous, persisting for varying lengths of time under constant laboratory conditions (see Gibson 1982 for a revision).

Gibson $(1967,1969)$ compared the rhythmic behaviour of intertidal fish with that of closely related species that are subtidal, or live in conditions where the tides are negligible, such as the Mediterranean. These studies showed repeatedly that the non-intertidal species fail to display tidal-driven rhythms in the laboratory.

Although the studies on tidal rhythms mentioned above demonstrate that tidally driven clocks persist under constant laboratory conditions, they often provide little insight into the environmental stimuli that are effective in keeping them synchronized with the tidal cycle. A remarkable exception was the experimental work by Gibson (1971), which demonstrates that for Lipophrys pholis mere fluctuations in hydrostatic pressure are sufficient to keep the tidal rhythm entrained. In typical natural situations, the physical, chemical and biological variables that change with the tide are numerous, so the number of potential cues that can affect the behaviour of fish is also high.

In this note we took advantage of the construction of a semi-natural pool that changed the typical intertidal conditions and reduced the number of variables that change 
with the tidal cycle within its confined space, providing a kind of "field experiment" that we believe may shed some light on the factors that control the behaviour of rocky shore fish.

\section{Materials and methods}

The study area was a semi-natural pool at Estoril, near the mouth of the Tagus river, in Portugal $\left(38^{\circ} 41^{\prime} \mathrm{N}, 9^{\circ} 22^{\prime} \mathrm{W}\right)$. This pool was created by building a concrete wall along a stretch of the rocky shore, a few meters from the coast and closed at both ends. The top of the wall lies bellow the high-water level, thus, during high tide water moves freely between the pool and the sea. However, when the tide ebbs the pool retains its water, so that the typical low-tide emersion never occurs. Contrary to a typical intertidal situation, the intertidal fish present in the area are never emersed. Furthermore, wave action is limited to high tide, except when the sea is rough and waves break over the wall. As a result, the effects of emersion and turbulence are virtually absent.

Observations were made along nine transects on three types of microhabitats: (1) horizontal rocky platforms, (2) vertical rock walls and (3) sand and stones on the bottom of the pool (three transects on each microhabitat). The rock walls were 1.0-1.6 m high, and water depth ranged from 1.8 to $3.8 \mathrm{~m}$ at low and high tides, respectively. Therefore, the platforms that were above the rock walls still had $0.2-$ $0.8 \mathrm{~m}$ of water above them at low tide and $2.2-2.8 \mathrm{~m}$ of water above them at high tide (spring tide data). Although this area was always under water, the algae and invertebrate cover differed among the microhabitats. The rocky platforms presented a typical intertidal cover, comprising Chtamalus sp., Patella sp. and Corallina sp., while the rock walls supported typical subtidal algae such as Asparagopsis armata, Nithophyllum sp., Colpomenia sp. and Cystoseira sp.
The observations were based on visual censuses made by snorkelling and scuba dives, always during day time. On each day, two dives (each of 1-h duration) were undertaken; one at the low tide and the other at high tide. A total of 20 dives were performed ( 10 dives at low tide and 10 at high tide). For each dive, the species, depth at which fish were observed and whether the fish was active or inactive was recorded on an underwater writing pad. A fish was considered active when it was observed feeding or performing the typical blenniid short bouts of movement. Fish that were hidden or motionless were classified as inactive.

To analyse the distribution of the different species on the three microhabitat surveyed at high tide and low tide, respectively, data from all observations were pooled and the resulting contingency tables were analysed with the simulation statistical procedure ACTUS (Estabrook and Estabrook 1989). This approach has the advantage of being free from the assumptions of traditional $\chi^{2}$ tests, and allows the assessment of the significance both of the entire table and the individual cells. The number of fish recorded at the high and low tide observations of each day were compared with Wilcoxon match pairs test, as implemented in the computer program Statistica for Windows (ver. 4.5, C. Statsoft Inc. 1993).

\section{Results}

When comparing the number of fish of each species observed on the different microhabitats at high and low water (Table 1), several significant differences are apparent (low tide: $\chi^{2}=255.36, d . f .=10, p<0.001$; high tide: $\chi^{2}=$ 446.56, d.f. $=10, p<0.001)$. Parablennius pilicornis and Tripterygion delaisi were mainly present on the rock walls at low tide and on the rock bottom at high tide, never being observed on the rocky platform. All other species recorded were present on all microhabitats at all tidal phases. Both $L$. pholis and $C$. galerita were much more abundant on the

Table 1 Numbers of individual fish representing each species recorded utilising three microhabitats at high and low tide in a modified intertidal environment (the numbers of fish of each species recorded during all observations were pooled)

\begin{tabular}{|c|c|c|c|c|c|c|}
\hline & \multicolumn{3}{|c|}{ High tide } & \multicolumn{3}{|c|}{ Low tide } \\
\hline & Bottom & Rock wall & Rocky platform & Bottom & Rock wall & Rocky platform \\
\hline Coryphoblennius galerita & 8 & 28 & 150 & 5 & 10 & 5 \\
\hline Lipophrys pholis & 0 & 28 & 450 & 8 & 38 & 98 \\
\hline Lipophrys trigloides & 11 & 2 & 13 & 6 & 2 & 20 \\
\hline Parablennius gattorugine & 8 & 15 & 10 & 30 & 15 & 5 \\
\hline Parablennius pilicornis & 10 & 0 & 0 & 13 & 28 & 0 \\
\hline Tripterygium delaisi & 10 & 10 & 0 & 10 & 88 & 0 \\
\hline
\end{tabular}


rocky platform in both tidal phases considered (68-94\% for L. pholis and $25-81 \%$ for C. galerita). Lipophrys trigloides was more abundant on the platform especially during low tide. Parablennius gattorugine was more abundant on the bottom or on the rock wall than on the platform, but there were always some individuals present on the platform, especially during high tide.

Both $L$. pholis and C. galerita were significantly more visible and were more active during high tide (Wilcoxon match pairs tests: $Z=2.70, p<0.01, N=10$ and $Z=2.80, p<$ $0.05, N=10$ respectively). During low tide, both species were mostly inactive on the substratum or near a topographic feature. In the case of L. pholis, fish were often observed in small groups, with fish laying still in close contact with one another. In contrast, $P$. pilicornis was significantly more active during low tide (Wilcoxon match pairs tests: $Z=2.37, p<0.05, N=10$ ). For the other two species, L. trigloides and P. gattorugine, there was no significant difference in their abundance between tides. For T. delaisi we lacked enough data for a reliable analysis.

\section{Discussion}

The three common intertidal species studied (C. galerita, $L$. pholis and L.trigloides) were present in all depths sampled, but were significantly more abundant in the upper zone (rocky platforms). On the contrary, two of the three subtidal species studied (P. pilicornis and T. delaisi) were restricted to deeper water (rock walls), although the upper limit of their distribution was very close to the rocky platform. $P$. gattorugine occurred in all depths studied, moving up during high tide. Faria and Almada (2006) reported the presence of both juveniles and adults of this species in the highest shore levels during high tide. Milton (1983) had already suggested that the adults of this species must migrate to some extent to the intertidal to feed. Thus, a first conclusion of the present study is that even without emersion at low tide, the typical separation of intertidal and subtidal fish tends to be preserved in this altered condition.

Two of the three intertidal species, L. pholis and $C$. galerita, presented a rhythmic activity, being less active during low tide, despite there being enough water to permit fish to move along the platform. L. trigloides was not observed to have any activity pattern related to the tidal cycle. On the other hand, this species seems to move to higher depths at high tide. Faria and Almada (2006) found this species to be restricted to the low intertidal during low tide, being more abundant in the subtidal during high tide. Thus, the two more specialized intertidal fish, L. pholis and C. galerita, retained their tidal activity rhythm even in conditions of permanent submersion and when water would allow free movement at low tide. This result is consistent with the hypothesis of Gibson (1971), which points to the role of tidal variations in water pressure as an important cue for the entrainment of fish tidal rhythms.

The observation of $L$. pholis during low tide deserves mention. This fish, which shows some level of agonistic behaviours even when juvenile (Gibson 1968; Faria et al. 1998), are observed sheltered out of water in groups of several individuals, under the protection of crevices, often packed in close contact with each other (Faria and Almada 2001). In the present study the formation of tight groups was also observed during low tide, demonstrating that this reduction of aggression and tolerance of contact of conspecifics in shelters is not caused by the lack of water and the need to use the available crevices.

In sharp contrast with $L$. pholis and $C$. galerita, the subtidal P. pilicornis was most active at low tide. Its habitat extends many meters into the subtidal, well below the zone where wave turbulence is important. It will be interesting in the future to see if its increase in activity at low tide is driven by an internal clock or merely reflects a behavioural mechanism that enables this fish to avoid swimming in turbulent conditions.

The results reported in this note, limited as they are, highlight the gaps in our knowledge of the behavioural mechanisms that may regulate the distribution of the rockyshore fishes and specifically the relative contributions of internal clocks and immediate responses to environmental stimuli. Such an understanding is not only a challenge for those interested in the physiological mechanisms controlling rhythmic behaviour, but to assess the role of behaviour in structuring the rocky shore fish communities, niche segregation and differential use of microhabitats by different species.

Acknowledgements Part of this study was supported by Fundação para a Ciência e Tecnologia (FCT) within the Plurianual Program (UI\&D 331/94, partially FEDER funded) and by FCT and FEDER within the project POCTI/BSE/46825/2002. C.F. was also supported by a grant from FCT (SFRH/BPD/14478/2003). We thank C. Silva who helped with the field work.

\section{References}

Estabrook CB, Estabrook GF (1989) ACTUS: a solution to the problem of small samples in the analysis of two-way contingency tables. Hist Methods 22:5-8

Faria C, Almada V (2001) Microhabitat segregation in three rocky intertidal fish species in Portugal: does it reflect interspecific competition. J Fish Biol 58:145-159

Faria C, Almada VC (2006) Patterns of spatial distribution and behaviour of fish on a rocky intertidal platform at high tide. Mar Ecol Prog Ser 316:155-164

Faria C, Almada V, Nunes MC (1998) Patterns of agonistic behaviour, shelter occupation and habitat preference in juvenile Lipophrys 
pholis, Coryphoblennius galerita and Gobius cobitis. J Fish Biol 53:1263-1273

Gibson RN (1967) Experiments on the tidal rhythm of Blennius pholis. J Mar Biol Assoc UK 47:97-111

Gibson RN (1968) The agonistic behaviour of juvenile Blennius pholis L. (Teleostei). Behaviour 30:192-217

Gibson RN (1969) Activity rhythms in two species of Blennius from the Mediterranean. Vie Milieu 20:235-244

Gibson RN (1970) The tidal rhythm of activity of Coryphoblennius galerita (L.) (Teleostei, Blenniidae). Anim Behav 18:529-543

Gibson RN (1971) Factors affecting the rhythmic activity of Blennius pholis L. (Teleostei). Anim Behav 19:336-343
Gibson RN (1972) The vertical distribution and feeding relationships of intertidal fish on the Atlantic coast of France. J Anim Ecol 41:189-207

Gibson RN (1982) Recent studies on the biology of intertidal fishes. Oceanogr Mar Biol Annu Rev 20:363-414

Gibson RN (1986) Intertidal teleosts: life in a fluctuating environment. In: Pitcher TJ (ed) The behaviour of teleost fishes. Croom Helm, London, pp 388-408

Horn MH, Martin KLM, Chotkowski MA (1999) Intertidal fishes. Life in two worlds. Academic, London

Milton P (1983) Biology of littoral blenniid fishes of the coast of south-west England. J Mar Biol Assoc UK 63:223-237 